\title{
Overexpression of UTX promotes tumor progression in Oral tongue squamous cell carcinoma patients receiving surgical resection: a case control study
}

\author{
Yen-Hao Chen ${ }^{1,2,3}$, Chang-Han Chen ${ }^{4}$, Chih-Yen Chien ${ }^{5}$, Yan-Ye Su ${ }^{5}$, Sheng-Dean Luo ${ }^{5}$ and Shau-Hsuan Li ${ }^{1 *}$
}

\begin{abstract}
Background: Ubiquitously transcribed tetratricopeptide repeat on chromosome X (UTX) has been identified as a histone 3 lysine 27 (H3K27) demethylase and acted as a tumor suppressor gene or oncogenic function. The current study was to explore the significance of UTX in oral tongue squamous cell carcinoma (OTSCC) patients who received surgical resection.

Methods: A total of 148 OTSCC patients who underwent surgical resection were identified, including 64 patients (43\%) with overexpression of UTX and 84 patients (57\%) harboring low expression of UTX. We also used two OTSCC cell lines, SAS and Cal 27, to determine the modulation of cancer. Chi-square test was used to investigate the difference of categorical variables between the groups; survival outcome was analyzed using the Kaplan-Meier method in univariate analysis, and a Cox regression model was performed for multivariate analyses.

Results: Univariate and multivariate analyses showed overexpression of UTX were significantly related to worse disease-free survival $(P=0.028)$ and overall survival $(P=0.029)$. The two OTSCC cell lines were treated with GSK-J4, a potent inhibitor of UTX, and transwell migration and invasion assays showed an inhibitory effect with a dosedependent manner. In addition, western blot analyses also revealed the inhibition of cell cycle and epithelialmesenchymal transition.
\end{abstract}

Conclusion: Our study suggests that UTX plays an important role in the process of OTSCC and overexpression of UTX may predict poor prognosis in OTSCC patients who received surgical resection.

Keywords: UTX, Tongue cancer, Squamous cell carcinoma, Surgery

\section{Background}

Oral cavity cancer is one of the most aggressive cancers worldwide. The tongue is the most commonly occurring site for oral cavity cancers; such cancers are usually squamous cell carcinomas. Oral tongue squamous cell

\footnotetext{
* Correspondence: lee.a0928@msa.hinet.net

'Department of Hematology-Oncology, Kaohsiung Chang Gung Memorial Hospital and Chang Gung University College of Medicine, No.123, Dapi Rd., Niaosong Dist, Kaohsiung City 833, Taiwan

Full list of author information is available at the end of the article
}

carcinoma (OTSCC) has the highest incidence, and while the incidence generally has increased, the five-year survival rates have not improved over the last 20 years $[1,2]$. OTSCC usually migrates rapidly to the adjacent structures and disseminates to other organs through the bloodstream and lymphatic drainage. Surgical resection remains the gold standard for operable disease, and adjuvant chemotherapy, radiotherapy, or combination therapy is indicated for high-risk populations, in clinical practice [3]. The important risk factors of poor

(c) The Author(s). 2021 Open Access This article is licensed under a Creative Commons Attribution 4.0 International License, which permits use, sharing, adaptation, distribution and reproduction in any medium or format, as long as you give appropriate credit to the original author(s) and the source, provide a link to the Creative Commons licence, and indicate if changes were made. The images or other third party material in this article are included in the article's Creative Commons licence, unless indicated otherwise in a credit line to the material. If material is not included in the article's Creative Commons licence and your intended use is not permitted by statutory regulation or exceeds the permitted use, you will need to obtain permission directly from the copyright holder. To view a copy of this licence, visit http://creativecommons.org/licenses/by/4.0/ The Creative Commons Public Domain Dedication waiver (http://creativecommons.org/publicdomain/zero/1.0/) applies to the data made available in this article, unless otherwise stated in a credit line to the data. 
prognosis in OTSCC include depth of invasion, perineural invasion, lymphovascular invasion, increasing pathological $\mathrm{T}$ and $\mathrm{N}$ stage, extracapsular extension, and surgical margin [4-8]. These risk factors lead to an increasing incidence of locoregional failure and distant metastasis, contributing to poor prognosis and impaired quality of life $[9,10]$. Thus, it is of great significance to identify a potential biomarker associated with tumor progression to improve prognosis in OTSCC patients.

Ubiquitously transcribed tetratricopeptide repeat on chromosome X (UTX)-also known as KDM6A-is a histone demethylase that targets di- and tri-methylated histone H3 lysine 27 (H3K27); it is involved in embryonic development, tissue-specific differentiation, and cancer growth [11, 12]. Growing evidence has shown that UTX mutations or deregulation are associated with several cancer types, including breast cancer, bladder cancer, colon cancer, and B-cell lymphoma [13-17]. However, the role of UTX in tumor suppression or in the enhancement of cancer cell proliferation still remains controversial. In breast cancer, blocking UTX resulted in a significant decrease in tumor cell proliferation and invasion in cell lines and in a mouse xenograft model. In addition, breast cancer patients showing overexpression of UTX were reported to have poor prognosis [13]. On the other hand, UTX is often associated with somatic loss-of-function mutations in several cancer types such as renal carcinoma, acute leukemia, medulloblastoma, etc. [18]. In addition, UTX transcriptionally activates Retinoblastoma $(\mathrm{Rb})$ genes to inhibit tumor cell proliferation in several tumor types, suggestion that UTX is a tumor suppressor [19].

However, the role of UTX in OTSCC still remains unclear. We suppose that UTX overexpression is a novel mechanism contributing to the promotion of tumor cell proliferation in OTSCC patients. The aim of the current study was to investigate the role of UTX in the prognosis of OTSCC patients who underwent surgical resection.

\section{Methods}

\section{Patient selection}

Between January 2006 and December 2015, 1059 patients who were diagnosed with OTSCC at Kaohsiung Chang Gung Memorial Hospital were retrospectively reviewed. Patients with a history of a second primary malignancy or a distant metastasis-whether before or after the diagnosis of OTSCC-were excluded. Subsequently, those who received neoadjuvant treatment such as chemotherapy, radiotherapy, or combination therapy were also excluded, and patients who underwent curative surgical resection were selected. Among these, only patients with available paraffin embedded tissue blocks were enrolled. Finally, a total of 148 OTSCC patients were identified.

The Eastern Cooperative Oncology Group (ECOG) Scale of Performance Status (PS) is one such measurement and describes a patient's level of functioning in terms of their ability to care for themselves, daily activity, and physical ability. All patients in our study were ECOG PS 0 or 1; PS 0 means normal activity and PS 1 means some symptoms, but still near fully ambulatory.

\section{Immunohistochemistry}

In our study, all patients received glossectomy. The tissue blocks from the formalin-fixed paraffin waxembedded OTSCC tissue (from glossectomy sample, not from biopsy sample) were cut to prepare sections with $4-\mu \mathrm{m}$ thickness. For each patient, all slides from the glossectomy sample were carefully reviewing by two pathologists (WT Huang and SL Wang) and one slide which is the most significant for the OTSCC was selected for further investigation. First, the sections were subjected to deparaffinization by incubating them in a dry oven at $60^{\circ} \mathrm{C}$ for $1 \mathrm{~h}$, antigen retrieval using $10 \mathrm{mM}$ citrate buffer ( $\mathrm{pH}$ 6.0), followed by incubation in a hot water bath $\left(95^{\circ} \mathrm{C}\right)$ for $20 \mathrm{~min}$, and peroxidase blocking using $0.3 \%$ hydrogen peroxide for $5 \mathrm{~min}$. Then, a primary antibody against UTX (ab235989, 1:2000, Abcam, Cambridge, MA, USA) was added to the sections and allowed to react; subsequently, a ready-to-use visualization reagent consisting of a goat secondary antibody was added to the sections and was allowed to react. The tissue sections were then incubated with a polymer for $8 \mathrm{~min}$, followed by staining with 3,3'-diaminobenzidine for $10 \mathrm{~min}$, and counterstaining with hematoxylin. The negative control group samples were stained using an identical procedure, while a slide of hepatocellular carcinoma cells was used as a positive control. The slides were scored by two pathologists (WT Huang and SL Wang) who were blinded to the clinicopathological features or prognosis. The method used for scoring the expression of UTX was determined according to a previous published study [20].

The proportions of UTX-expressing tumor cells were scored using the immunoreactive score (IRS) system which is calculated by the product of the multiplying the staining intensity (0: none; 1 : weak; 2 : moderate; and 3 : strong) and the percentage of positively stained cells (0: no staining; 1 : $<10 \%$ of the cells; $2: 11-50 \%$; 3 : $51-80 \%$; and 4: $>81 \%$ ), resulting in IRS scores between 0 (no staining) and 12 (maximum staining) [21]. A specimen with a sum score of $>6$ was regarded as having positive staining. 


\section{Cell lines and culture}

The OTSCC cell lines-SAS and Cal 27-were purchased from American Type Culture Collection and cultured in Dulbecco's modified Eagle's medium-nutrient mixture F-12 (Sigma-Aldrich). All culture media contained $10 \%$ fetal bovine serum. The cells were then cultured at $37^{\circ} \mathrm{C}$.

\section{Migration and invasion assays}

Transwell inserts (pore size $8 \mathrm{~mm}$; Corning, Glendale, AZ, USA) were used to evaluate cell migration, and Matrigel (BD Biosciences, San Jose, CA, USA) coated porous filters were used to examine cell invasion. Cells $\left(1 \times 10^{4}\right)$ in $200 \mathrm{ml}$ DMEM medium containing 10\% FBS were seeded into inserts, and $600 \mathrm{ml}$ was added in lower part of the well. Cells were incubated for $24 \mathrm{~h}$. Cells on the upper side of the membrane were wiped, and cells moving to the other side of the filters were stained by crystal violet and counted using a microscope in three randomly selected fields. Independent experiments were repeated three times.

\section{Western blot analysis}

Whole-cell lysates of GSK-J4-treated cells were extracted with $300 \mu \mathrm{L}$ of RIPA buffer ( $50 \mathrm{mM}$ Tris, $150 \mathrm{mM} \mathrm{NaCl}$, $1 \%$ NP40, $0.5 \%$ sodium deoxycholate, and $0.1 \%$ sodium dodecyl sulfate [SDS]), and subjected to western blot analysis. The membranes were incubated with polyclonal antibodies against UTX (ab36938, 1:2000, Abcam, Cambridge, MA, USA), Tri-methylation of histone H3 lysine 27 (H3K27me3) (A-4039, 1:2000, EpiGentek, Farmingdale, New York, USA), CDK4 (\#12790, 1:1000, cell signaling, Danvers, Massachusetts, USA), Cyclin D1 (\#2978, 1:1000, cell signaling, Danvers, Massachusetts, USA), Ecadherin (GTX124178, 1:5000, Genetex, Irvine, CA, USA), N-cadherin (sc-7939, 1:500, Santa Cruz Biotechnology, Santa Cruz, California, USA), Twist1 (\#46702S, 1:500, cell signaling, Danvers, Massachusetts, USA), and $\beta$-actin (A5441, 1:10000, Sigma-Aldrich, St. Louis, Missouri, USA). Horseradish peroxidase-conjugated antirabbit secondary antibody was added to detect primary antibodies, and blots were developed with a chemiluminescence system (Pierce). All resolved protein bands were developed using the Western Lightning Chemiluminescence Reagent Plus system (Amersham Biosciences). All the experiments were repeated at least three times with similar results.

\section{Ethics statement}

Ethical approval for this study was obtained from the Chang Gung Medical Foundation Institutional Review Board (201901388B0). All procedures used in studies involving human participants were performed in accordance with the ethical standards of the institutional research committee and the World Medical Association Declaration of Helsinki. Written informed consent was waived by the Chang Gung Medical Foundation Institutional Review Board.

\section{Statistical analysis}

Data of baseline characteristics were expressed as number and percentages appropriately. The chisquare test was used for comparing categorical variables. Disease-free survival (DFS) was defined as the time from surgery to recurrence of tumor or death from any cause without evidence of recurrence. Overall survival (OS) was calculated from the time of diagnosis of OTSCC to death or to the time of last living contact. Univariate analysis was performed using the Kaplan-Meier method, and differences were assessed with the log-rank test. The Cox proportional hazards model was used to identify independent prognostic factors in multivariate analysis. The statistical analysis was performed according to the protocol described in the previously published study [22].

We carried out all statistical analyses using SPSS software (International Business Machines Corp., New York, USA). A two-tailed $p$ value of $<0.05$ was considered to indicate statistical significance in all analyses.

\section{Results}

\section{Patient characteristics}

Between January 2006 and December 2015, a total of 148 OTSCC patients who received surgical resection at Kaohsiung Chang Gung Memorial Hospital were enrolled in the study. All of these patients had an Eastern Cooperative Oncology Group performance status $\leq 1$. In our study, we enrolled 135 male patients and 13 female patients with a median age of 53 years (range: 26-86 years). A history of smoking was found in 122 patients (82\%), alcohol consumption in 118 patients (80\%), and betel-nut chewing was mentioned in 112 patients (76\%). Forty-two patients (29\%) had pathological T1 status, 48 patients (32\%) had pathological T2 status, 12 patients (8\%) had pathological T3 status, and 46 patients (31\%) had pathological T4 status; the pathological $\mathrm{N}$ status data revealed 79 patients (54\%) diagnosed as N0, 24 patients $(16 \%)$ as N1, 42 patients $(28 \%)$ as N2, and three patients $(2 \%)$ as N3. There were 31 patients $(21 \%)$ with stage I, 29 patients (20\%) with stage II, 23 patients (15\%) with stage III, 58 patients (39\%) with stage IVA, and seven patients $(5 \%)$ with stage IVB disease. The tumor grade data showed that 84 patients $(57 \%)$ had grade 1 , 59 patients $(40 \%)$ had grade 2 , and five patients $(3 \%)$ had grade 3 tumors.

In our study, the median period of follow-up was 82.5 months (range: 60.7-110.6 months) for the 63 living survivors and 52.4 months (range: 1.0-110.6 months) for 
Table 1 Characteristics of 148 patients with oral tongue squamous cell carcinoma receiving surgical resection

Age (years)

Sex

Pathological T status

11

T2

T3

$\mathrm{T} 4 \mathrm{a}$

$\mathrm{T} 4 \mathrm{~b}$

Pathological N status

female

$13(9 \%)$

42 (29\%)

48 (32\%)

$12(8 \%)$

41 (28\%)

$5(3 \%)$

79 (54\%)

24 (16\%)

42 (28\%)

$3(2 \%)$

Pathological 8th AJCC Stage

$$
\text { । }
$$

॥

III

IVA

IVB

31 (21\%)

29 (20\%)

23 (15\%)

58 (39\%)

7 (5\%)

Histologic grade

1

84 (57\%)

59 (40\%)

$5(3 \%)$

UTX expression

\section{Overexpression}

64 (43\%)

Low expression

84 (57\%)

Vascular invasion

Absent

124 (84\%)

Present

24 (16\%)

Perineural invasion

Absent

81 (55\%)

Present

67 (45\%)

Extracapsular extension

Absent

111 (75\%)

Present

37 (25\%)

Surgical margin

Negative

137 (93\%)

Positive

$11(7 \%)$

Absent

$26(18 \%)$

Present 
Table 1 Characteristics of 148 patients with oral tongue squamous cell carcinoma receiving surgical resection (Continued)

\begin{tabular}{|c|c|c|}
\hline Age (years) & 53 (range: 26-86) & \\
\hline \multicolumn{3}{|l|}{ Alcohol } \\
\hline & Absent & $30(20 \%)$ \\
\hline & Present & $118(80 \%)$ \\
\hline \multicolumn{3}{|c|}{ Betel-nut chewing } \\
\hline & Absent & $36(24 \%)$ \\
\hline & Present & $112(76 \%)$ \\
\hline
\end{tabular}

AJCC, American Joint Committee on Cancer

all 148 patients. The five-year DFS and OS rates were 44.6 and $47.3 \%$, respectively. The relevant details are shown in Table 1.

\section{UTX and clinical outcome}

The mechanism of UTX in the tumor cell progression was shown in Fig. 1. The expression of UTX in immunohistochemical staining is shown in Fig. 2. Among the 148 patients, there were 64 patients (43\%) with overexpression of UTX, and 84 patients (57\%) showing a low expression of UTX. No significant difference in baseline characteristics including age, sex, pathological $\mathrm{T}$ status, histologic grade, vascular invasion, perineural invasion, surgical margin, cigarette smoking, alcohol consumption, and betel-nut chewing was observed between groups categorized based on UTX expression levels. Patients showing UTX overexpression had a higher percentage of pathological $\mathrm{N}$ status and tumor stage compared to those with low expression of UTX. The comparison is shown in Table 2.

With respect to DFS, a univariate analysis found that age, sex, histologic grade, surgical margin, smoking,

\section{a}
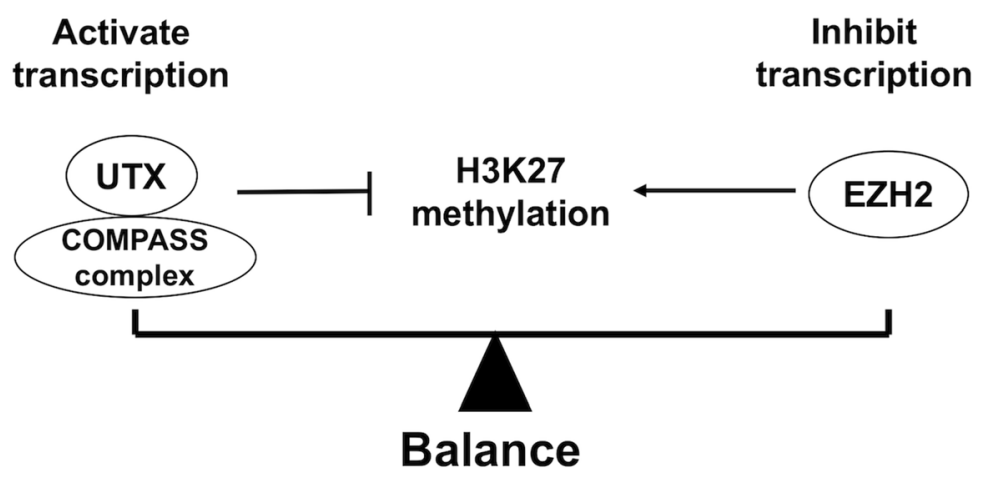

b
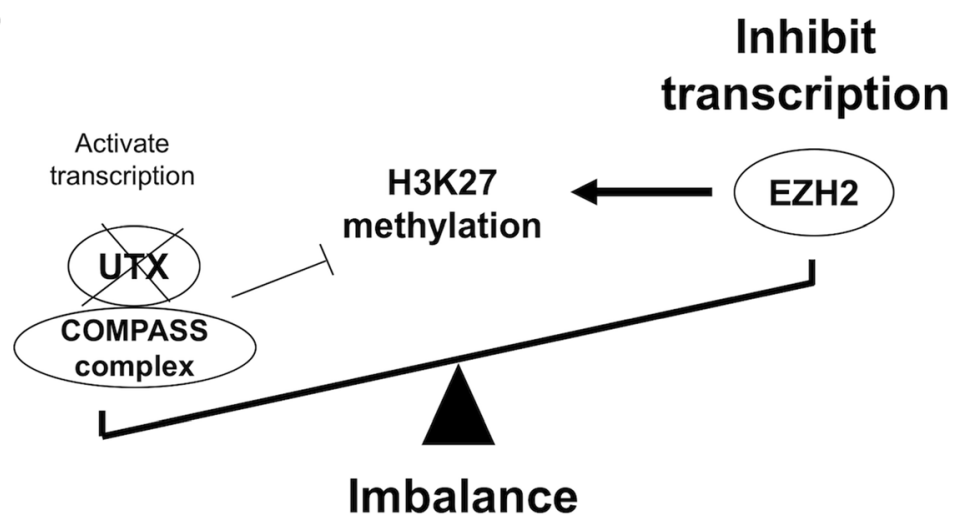

Fig. 1 The mechanism of UTX in the tumor progression. (a) Balance of H3K27 methylation between UTX and EZH2 function in the tumor cell transcription; (b) Loss of UTX induces increased H3K27 methylation, leading to inhibition of tumor cell transcription 


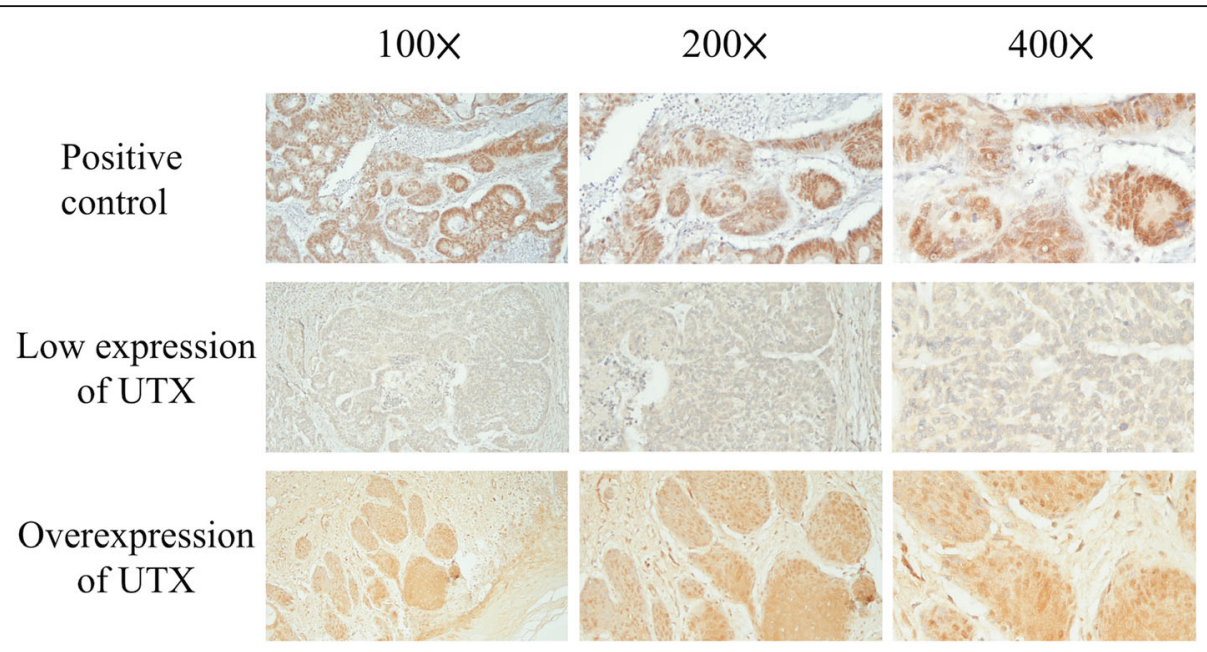

Fig. 2 Results of the immunohistochemical analysis of UTX in oral tongue squamous cell carcinoma patients

alcohol consumption, and betel-nut chewing were not statistically significant predictors of DFS. The 58 patients who had pathological T3-4 were found to have worse DFS than did the other 90 patients who had pathological T1--2 disease (11.4 months versus 69.8 months, $P=$ 0.004); 69 patients with nodal metastasis had shorter DFS in comparison with the other 79 patients without nodal metastasis $(13.2$ months versus 87.9 months, $P<$ 0.001). Significantly inferior DFS was found in the $88 \mathrm{pa}-$ tients who had pathological stage III-IV than in the 60 patients who had pathological stage I-II disease (13.4 months versus not reached, $P=0.001)$. Patients who had positive vascular invasion, perineural invasion, and extracapsular extension were mentioned to have inferior DFS compared to those who did not $(P=0.018, P=0.008$, $P<0.001$, respectively). The 64 patients who showed an overexpression of UTX had worse DFS than did the other 84 patients with a low expression of UTX (20.6 months versus 69.8 months, $P=0.006$, Fig. $3 \mathrm{~A})$. In a multivariate analysis, extracapsular extension $(\mathrm{P}<0.001$, hazard ratio (HR): 2.22 , 95\% confidence interval $(\mathrm{CI})$ : $1.43-3.47)$ and overexpression of UTX $(P=0.028$, HR: 1.61, 95\% CI: $1.05-2.45)$ were independent prognostic parameters of worse DFS.

In the analysis of OS, no statistically significant differences in parameters such as age, sex, histologic grade, alcohol consumption, and betel-nut chewing were observed in univariate analysis. The 58 patients with pathological T3-4 were found to have inferior OS compared to the other 90 patients with pathological T1-2 disease (13.2 months versus 82.2 months, $P<0.001$ ); 69 patients who had nodal metastasis had worse OS compared to the other 79 patients without nodal metastasis (14.8 months versus not reached, $\mathrm{P}<0.001)$. Significantly inferior OS was observed in the 88 patients with pathological stage III-IV compared to that in the 60 patients with pathological stage I-II disease (22.5 months versus not reached, $P<0.001)$. Patients who had positive vascular invasion, perineural invasion, extracapsular extension, surgical margin, and smoking history were found to have shorter OS than those who did not $(P=0.004, P=0.022$, $\mathrm{P}<0.001, P=0.031$, and $\mathrm{P}=0.031$, respectively). The 64 patients who showed an overexpression of UTX had worse OS than did the other 84 patients with a low expression of UTX (23.0 months versus 69.8 months, $P=$ 0.006, Fig. 3B). Multivariate analysis showed that advanced pathological $\mathrm{T}$ status $(P=0.015, \mathrm{HR}: 1.73,95 \%$ CI: $1.11-2.69)$, extracapsular extension $(P=0.003$, HR: 2.01, 95\% CI: $1.26-3.21)$ and overexpression of UTX $(P=0.029$, HR: $1.61,95 \%$ CI: $1.05-2.48)$ were independent prognostic factors of worse OS. The survival outcomes in the univariate and multivariate analyses are shown in Tables 3 and 4.

\section{Inhibition of UTX by GSK-J4 decrease the abilities of migration and invasion of OTSCC}

Accumulating evidence indicated that GSK-J4, a pharmacologic inhibitor, is able to inhibit UTX activity that acts on specifically H3K27me3 which participates in cancer progression. To analyze the effect of UTX in OTSCC, we determined the cellular motility of OTSCC with GSK-J4 treatment by Transwell assay. Transwell assay results revealed that cells treated with GSK-J4 in a dose-dependent manner significantly reduced the number of invaded and migrated cells, compared to cells without GSK-J4 treatment (Fig. 4). The observation demonstrated that, at least in SAS and Cal27 cell lines, inhibition of UTX by GSK-J4 could suppress the motility of OTSCC. Furthermore, the Western blot analyses were performed to determine the expressions of UTX, H3K27me3 status, EMT (epithelial-mesenchymal transition), and GSK-J4-regulated targets in the OTSCC cell 
Table 2 Associations between UTX expression and clinicopathological parameters in 148 patients with oral tongue squamous cell carcinoma receiving surgical resection

\begin{tabular}{|c|c|c|c|c|}
\hline \multirow[t]{2}{*}{ Parameters } & & \multicolumn{3}{|l|}{ UTX expression } \\
\hline & & Overexpression $(N=64)$ & Low expression $(N=84)$ & $P$ value \\
\hline \multicolumn{5}{|l|}{ Age } \\
\hline & $<53 y / 0$ & $31(48 \%)$ & $39(46 \%)$ & \multirow[t]{2}{*}{0.81} \\
\hline & $\geqq 53 \mathrm{y} / \mathrm{o}$ & $33(52 \%)$ & $45(54 \%)$ & \\
\hline \multicolumn{5}{|l|}{ Sex } \\
\hline & male & $58(91 \%)$ & 77 (92\%) & \multirow[t]{2}{*}{0.82} \\
\hline & female & $6(9 \%)$ & $7(8 \%)$ & \\
\hline \multicolumn{5}{|c|}{ Pathological T status } \\
\hline & $\mathrm{T} 1+\mathrm{T} 2$ & $34(53 \%)$ & $56(67 \%)$ & \multirow[t]{2}{*}{0.10} \\
\hline & $\mathrm{T} 3+\mathrm{T} 4$ & $30(47 \%)$ & $28(33 \%)$ & \\
\hline \multicolumn{5}{|c|}{ Pathological N status } \\
\hline & No & $27(42 \%)$ & $52(62 \%)$ & \multirow[t]{2}{*}{$0.017^{*}$} \\
\hline & $\mathrm{N} 1+2+3$ & $37(58 \%)$ & $32(38 \%)$ & \\
\hline \multicolumn{5}{|c|}{ Pathological 8th AJCC Stage } \\
\hline & $1+\|$ & 19 (30\%) & $41(49 \%)$ & \multirow[t]{2}{*}{$0.019^{*}$} \\
\hline & $I I I+I V$ & $45(70 \%)$ & $43(51 \%)$ & \\
\hline \multicolumn{5}{|c|}{ Histologic grade } \\
\hline & 1 & $38(59 \%)$ & $46(55 \%)$ & \multirow[t]{2}{*}{0.58} \\
\hline & $2+3$ & $26(41 \%)$ & $38(45 \%)$ & \\
\hline \multicolumn{5}{|c|}{ Vascular invasion } \\
\hline & Absent & $53(83 \%)$ & $71(85 \%)$ & \multirow[t]{2}{*}{0.78} \\
\hline & Present & $11(17 \%)$ & $13(15 \%)$ & \\
\hline \multicolumn{5}{|c|}{ Perineural invasion } \\
\hline & Absent & $31(48 \%)$ & $50(60 \%)$ & \multirow[t]{2}{*}{0.18} \\
\hline & Present & $33(52 \%)$ & $34(40 \%)$ & \\
\hline \multicolumn{5}{|c|}{ Extracapsular extension } \\
\hline & Absent & $43(67 \%)$ & $68(81 \%)$ & \multirow[t]{2}{*}{0.06} \\
\hline & Present & $21(33 \%)$ & 16 (19\%) & \\
\hline \multicolumn{5}{|c|}{ Surgical margin } \\
\hline & Negative & $58(91 \%)$ & 79 (94\%) & \multirow[t]{2}{*}{0.43} \\
\hline & Positive & $6(9 \%)$ & $5(6 \%)$ & \\
\hline \multicolumn{5}{|c|}{ Smoking history } \\
\hline & Absent & $12(19 \%)$ & $14(17 \%)$ & \multirow[t]{2}{*}{0.74} \\
\hline & Present & 52 (81\%) & 70 (83\%) & \\
\hline \multicolumn{5}{|c|}{ Alcohol history } \\
\hline & Absent & $11(17 \%)$ & 19 (23\%) & \multirow[t]{2}{*}{0.42} \\
\hline & Present & $53(83 \%)$ & 65 (77\%) & \\
\hline Betel-nut che & & & & \\
\hline & Absent & $11(17 \%)$ & $25(30 \%)$ & 0.08 \\
\hline & Present & 53 (83\%) & 59 (70\%) & \\
\hline
\end{tabular}

AJCC, American Joint Committee on Cancer. *Statistically significant 

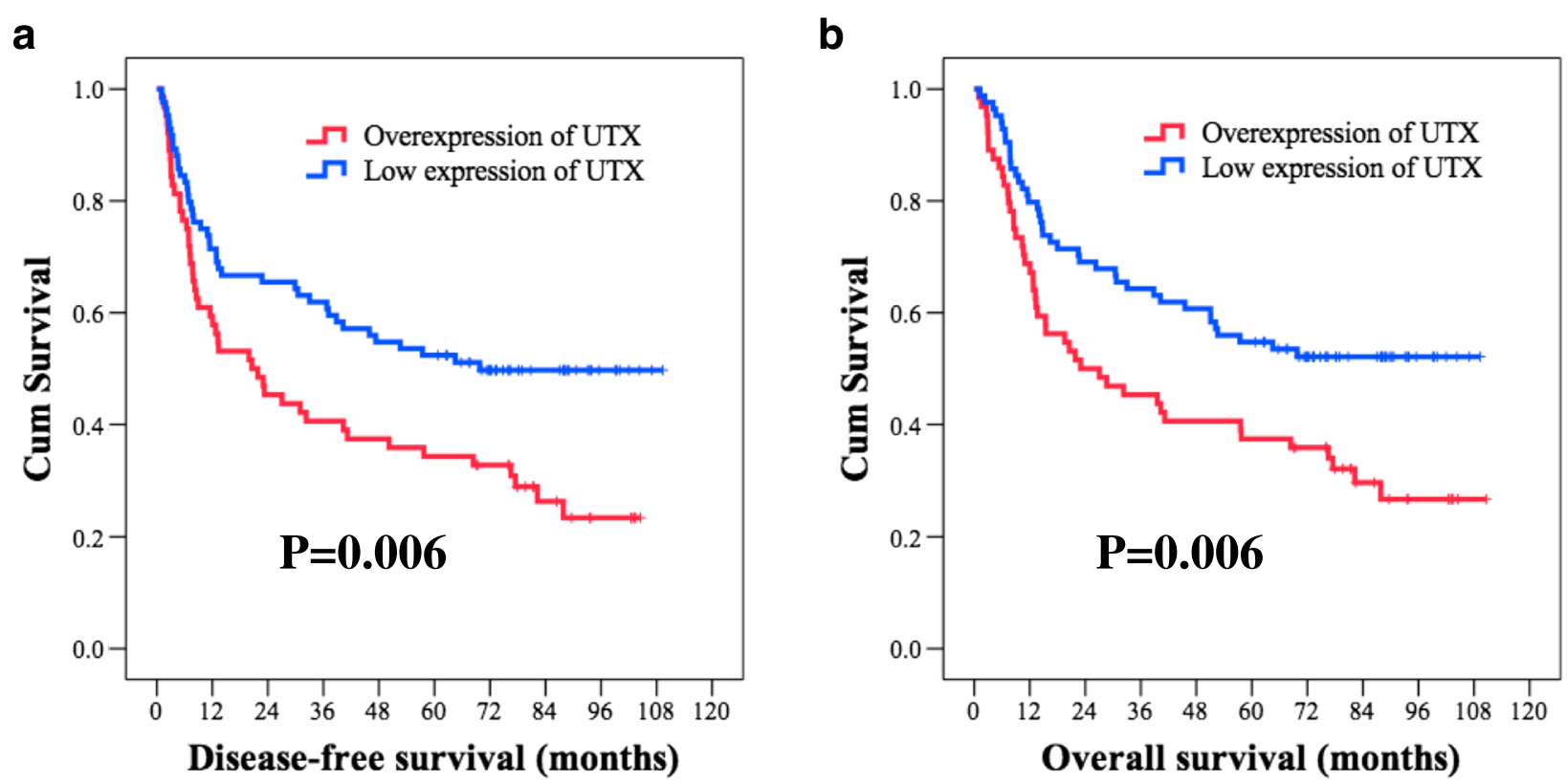

Fig. 3 Comparison of Kaplan-Meier curves in oral tongue squamous cell carcinoma patients with high and low expression of UTX. (a) Disease-free survival (b) Overall survival

lines upon GSK-J4 treatment. Our data showed that the protein expressions of UTX, N-cadherin, Twist1, CDK4 and cyclin D1 were downregulation, but H3K27me3 status and E-cadherin were upregulation in GSK-J4-treated cell lines compared to that in the control cells (Fig. 5). Collectively, these data demonstrated that UTX expression participates in the motility of OTSCC.

\section{Discussion}

Histone demethylases are epigenetic regulators; they are involved in several cellular processes and in organogenesis. In addition, they are also associated with cancer, and play a crucial role of carcinogenesis, whether acting as oncogenes, or as tumor suppressor genes. H3K27me3 is regulated by the histone demethylase UTX, and results in conversion to H3K27me2 or H3K27me1; this results in a change in chromatin conformation from a repressive form to an active form [23]. UTX has been reported to be involved in the process of cancer, including growth, differentiation, migration, invasion, and apoptosis, through several signaling pathways; however, there is controversy regarding the expression pattern of UTX in different malignancies [13-16, 19].

In our study, the overexpression of UTX and extracapsular extension were independent prognostic factors of worse DFS and OS in both univariate and multivariate analyses. However, the role of UTX acting as an oncoprotein or as a tumor suppressor remains controversial. Growing evidences have shown that decreased H3K27me3 levels may result in tumor cell transcription and EMT, contributing to poor prognosis in some malignancies such as breast cancer, lung cancer and $\mathrm{T}$ cell acute lymphoblastic leukemia (T-ALL) [13, 24-27]. In general, there were balance between EZH2 and UTX and its protein interactors within the COMPASS complex, which activates and inhibits H3K27 methylation, respectively. Lower expression of UTX may result in an imbalance status, reduction of inhibiting H3K27 methylation by UTX and activation of H3K27 methylation by $\mathrm{EZH} 2$, contributing to tumor cell transcription and poor prognosis [26]. In lung adenocarcinoma, UTX and its COMPASS family member, MLL4, were statistically increased in brain metastasis compared to primary tumor; they also induced the expression of several EMTtranscription factors (TFs), such as ZEB1, Slug and Twist, indicating that UTX may regulate the expression of EMT-TFs epigenetically and affect distant metastasis [25]. In T-ALL, UTX is reported to be associated with TAL1, an oncogenic TF, and is recruited by TAL1 to its target genes. Suppression of UTX in several TAL1positive cell lines result in an increase in apoptosis, whereas overexpression of UTX enhances tumor cell proliferation [27]. Kim et al. reported that the inhibition of UTX resulted in significant reduction in the proliferation and invasiveness of breast cancer cells in vitro and in a mouse xenograft model [13]. Another study revealed UTX regulates the expression of estrogen receptor $\alpha$ target genes which are associated with development of breast cancer [16]. The loss of UTX leads to a significant reduction in estrogen-induced cell proliferation in a 
Table 3 Results of univariate and multivariable analyses of prognostic factors for disease-free survival (DFS) in 148 patients with oral tongue squamous cell carcinoma receiving surgical resection

\begin{tabular}{|c|c|c|c|c|c|c|}
\hline \multirow[t]{2}{*}{ Parameters } & & \multirow{2}{*}{$\begin{array}{l}\text { Number } \\
\text { of } \\
\text { patients }\end{array}$} & \multicolumn{2}{|c|}{ Univariate analysis } & \multicolumn{2}{|c|}{ Multivariable analysis } \\
\hline & & & DFS (months) & $P$ value & $\mathrm{HR}(95 \% \mathrm{Cl})$ & $P$ value \\
\hline \multicolumn{7}{|l|}{$\overline{\text { Age }}$} \\
\hline & $<53 y / 0$ & $70(47 \%)$ & 50.2 & 0.27 & & \\
\hline & $\geqq 53 y / 0$ & $78(53 \%)$ & 36.7 & & & \\
\hline \multicolumn{7}{|l|}{ Sex } \\
\hline & male & 135 (91\%) & 38.8 & 0.15 & & \\
\hline & female & $13(9 \%)$ & NR & & & \\
\hline \multicolumn{7}{|c|}{ Pathological T status } \\
\hline & $\mathrm{T} 1+\mathrm{T} 2$ & $90(61 \%)$ & 69.8 & $0.004^{*}$ & & \\
\hline & $\mathrm{T} 3+\mathrm{T} 4$ & $58(39 \%)$ & 11.4 & & & \\
\hline \multicolumn{7}{|c|}{ Pathological N status } \\
\hline & No & $79(53 \%)$ & 87.9 & $<0.001^{*}$ & & \\
\hline & $\mathrm{N} 1+2+3$ & $69(47 \%)$ & 13.2 & & & \\
\hline \multicolumn{7}{|c|}{ Pathological 8th AJCC Stage } \\
\hline & $1+\|$ & $60(41 \%)$ & NR & $0.001^{*}$ & & \\
\hline & $I I I+I V$ & $88(59 \%)$ & 13.4 & & & \\
\hline \multicolumn{7}{|c|}{ Histologic grade } \\
\hline & 1 & $84(57 \%)$ & 57.7 & 0.08 & & \\
\hline & $2+3$ & $64(43 \%)$ & 23.3 & & & \\
\hline \multicolumn{7}{|c|}{ Vascular invasion } \\
\hline & Absent & $124(84 \%)$ & 52.6 & $0.018^{*}$ & & \\
\hline & Present & $24(16 \%)$ & 11.0 & & & \\
\hline \multicolumn{7}{|c|}{ Perineural invasion } \\
\hline & Absent & $81(55 \%)$ & 77.5 & $0.008^{*}$ & & \\
\hline & Present & $67(45 \%)$ & 14.0 & & & \\
\hline \multicolumn{7}{|c|}{ Extracapsular extension } \\
\hline & Absent & $111(75 \%)$ & 64.5 & $<0.001^{*}$ & & \\
\hline & Present & $37(25 \%)$ & 7.9 & & $2.22(1.42-3.47)$ & $<0.001^{*}$ \\
\hline \multicolumn{7}{|c|}{ Surgical margin } \\
\hline & Negative & 137 (93\%) & 45.9 & 0.08 & & \\
\hline & Positive & $11(7 \%)$ & 12.8 & & & \\
\hline \multicolumn{7}{|c|}{ Smoking history } \\
\hline & Absent & $26(18 \%)$ & NR & 0.07 & & \\
\hline & Present & $122(82 \%)$ & 33.0 & & & \\
\hline \multicolumn{7}{|c|}{ Alcohol history } \\
\hline & Absent & $30(20 \%)$ & 47.3 & 0.54 & & \\
\hline & Present & $118(80 \%)$ & 33.0 & & & \\
\hline \multicolumn{7}{|c|}{ Betel-nut chewing history } \\
\hline & Absent & $36(24 \%)$ & 45.9 & 0.29 & & \\
\hline & Present & $112(76 \%)$ & 38.8 & & & \\
\hline \multicolumn{7}{|c|}{ UTX expression } \\
\hline & Overexpression & $64(43 \%)$ & 20.6 & $0.006^{*}$ & $1.61(1.05-2.45)$ & $0.028^{*}$ \\
\hline & Low expression & $84(57 \%)$ & 69.8 & & & \\
\hline
\end{tabular}

AJCC, American Joint Committee on Cancer. NR, not reach; HR, hazard ratio; Cl, confidence interval. *Statistically significant 
Table 4 Results of univariate and multivariable analyses of prognostic factors for overall survival (OS) in 148 patients with oral tongue squamous cell carcinoma receiving surgical resection

\begin{tabular}{|c|c|c|c|c|c|c|}
\hline \multirow[t]{2}{*}{ Parameters } & & \multirow{2}{*}{$\begin{array}{l}\text { Number } \\
\text { of } \\
\text { patients }\end{array}$} & \multicolumn{2}{|c|}{ Univariate analysis } & \multicolumn{2}{|c|}{ Multivariable analysis } \\
\hline & & & OS (months) & $P$ value & $\mathrm{HR}(95 \% \mathrm{Cl})$ & $P$ value \\
\hline \multicolumn{7}{|l|}{$\overline{\text { Age }}$} \\
\hline & $<53 y / 0$ & $70(47 \%)$ & 57.7 & 0.43 & & \\
\hline & $\geqq 53 y / 0$ & $78(53 \%)$ & 51.1 & & & \\
\hline \multicolumn{7}{|l|}{ Sex } \\
\hline & male & $135(91 \%)$ & 51.1 & 0.07 & & \\
\hline & female & $13(9 \%)$ & NR & & & \\
\hline \multicolumn{7}{|c|}{ Pathological T status } \\
\hline & $\mathrm{T} 1+\mathrm{T} 2$ & $90(61 \%)$ & 82.2 & $<0.001^{*}$ & & \\
\hline & $\mathrm{T} 3+\mathrm{T} 4$ & $58(39 \%)$ & 13.2 & & $1.73(1.11-2.69)$ & $0.015^{*}$ \\
\hline \multicolumn{7}{|c|}{ Pathological N status } \\
\hline & No & $79(53 \%)$ & NR & $<0.001^{*}$ & & \\
\hline & $\mathrm{N} 1+2+3$ & $69(47 \%)$ & 14.8 & & & \\
\hline \multicolumn{7}{|c|}{ Pathological 8th AJCC Stage } \\
\hline & $I+\|$ & $60(41 \%)$ & NR & $<0.001^{*}$ & & \\
\hline & $I I I+I V$ & $88(59 \%)$ & 22.5 & & & \\
\hline \multicolumn{7}{|c|}{ Histologic grade } \\
\hline & 1 & $84(57 \%)$ & 64.5 & 0.18 & & \\
\hline & $2+3$ & $64(43 \%)$ & 33.0 & & & \\
\hline \multicolumn{7}{|c|}{ Vascular invasion } \\
\hline & Absent & $124(84 \%)$ & 68.4 & $0.004^{*}$ & & \\
\hline & Present & $24(16 \%)$ & 11.4 & & & \\
\hline \multicolumn{7}{|c|}{ Perineural invasion } \\
\hline & Absent & $81(55 \%)$ & 82.2 & $0.022^{*}$ & & \\
\hline & Present & $67(45 \%)$ & 30.7 & & & \\
\hline \multicolumn{7}{|c|}{ Extracapsular extension } \\
\hline & Absent & $111(75 \%)$ & 76.5 & $<0.001^{*}$ & & \\
\hline & Present & $37(25 \%)$ & 11.7 & & $2.01(1.26-3.21)$ & $0.003^{*}$ \\
\hline \multicolumn{7}{|c|}{ Surgical margin } \\
\hline & Negative & $137(93 \%)$ & 57.6 & $0.031^{*}$ & & \\
\hline & Positive & $11(7 \%)$ & 13.2 & & & \\
\hline \multicolumn{7}{|c|}{ Smoking history } \\
\hline & Absent & $26(18 \%)$ & NR & $0.031^{*}$ & & \\
\hline & Present & $122(82 \%)$ & 40.3 & & & \\
\hline \multicolumn{7}{|c|}{ Alcohol history } \\
\hline & Absent & $30(20 \%)$ & 68.4 & 0.34 & & \\
\hline & Present & $118(80 \%)$ & 41.2 & & & \\
\hline \multicolumn{7}{|c|}{ Betel-nut chewing history } \\
\hline & Absent & $36(24 \%)$ & NR & 0.16 & & \\
\hline & Present & $112(76 \%)$ & 45.5 & & & \\
\hline \multicolumn{7}{|c|}{ UTX expression } \\
\hline & Overexpression & $64(43 \%)$ & 23.0 & $0.006^{*}$ & $1.61(1.05-2.48)$ & $0.029^{*}$ \\
\hline & Low expression & $84(57 \%)$ & 69.8 & & & \\
\hline
\end{tabular}

AJCC, American Joint Committee on Cancer. NR, not reach; HR, hazard ratio; Cl, confidence interval. *Statistically significant 


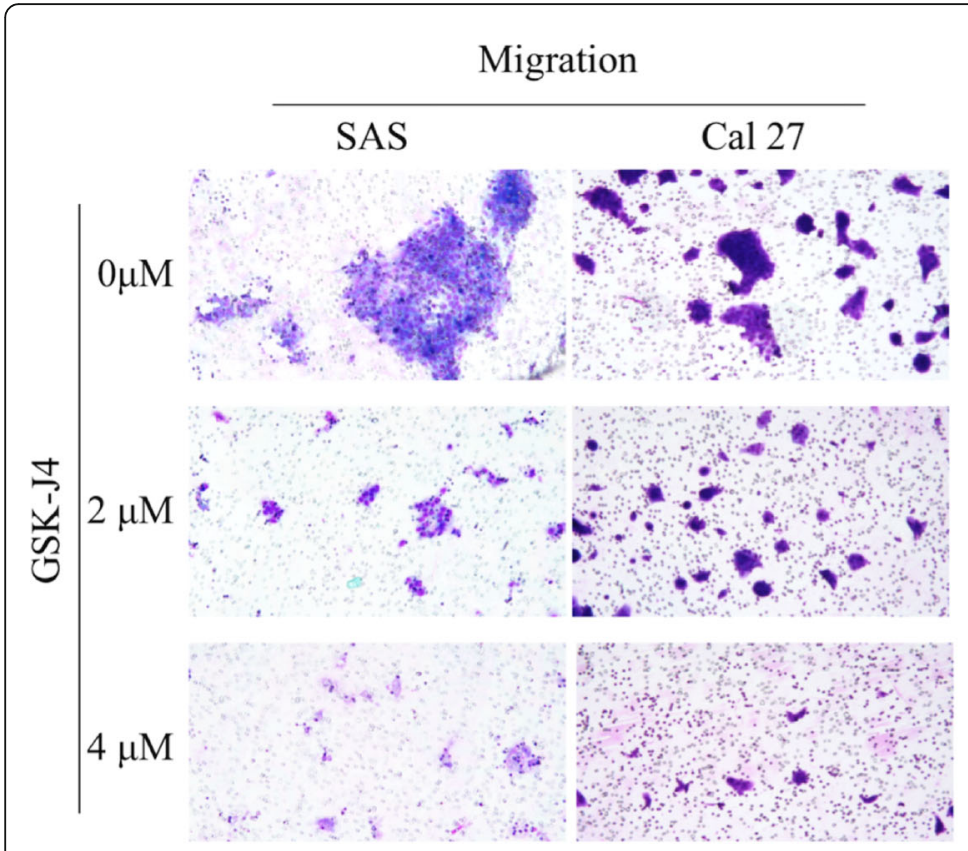

Invasion

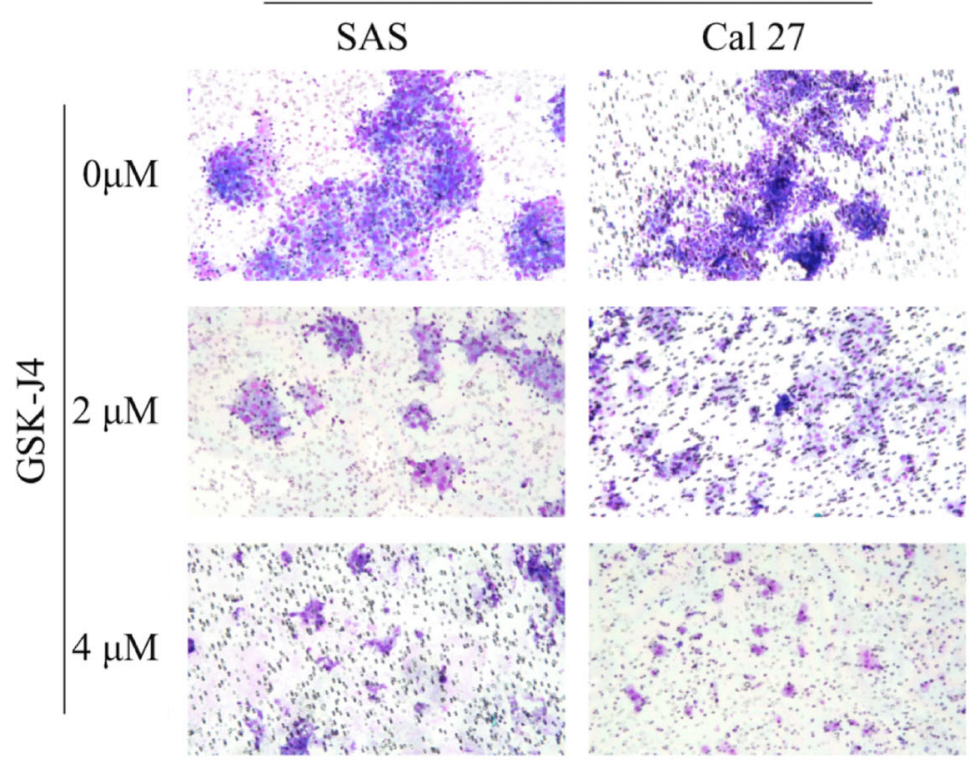

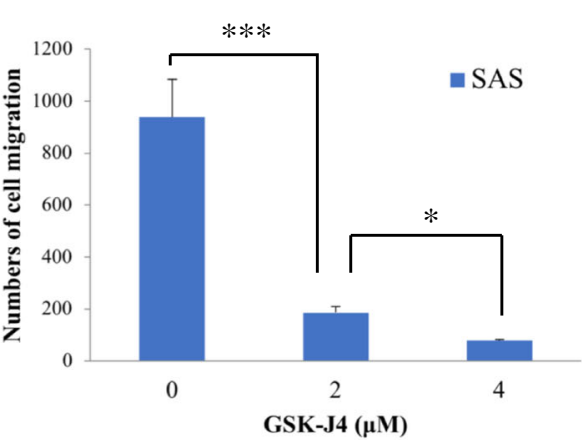
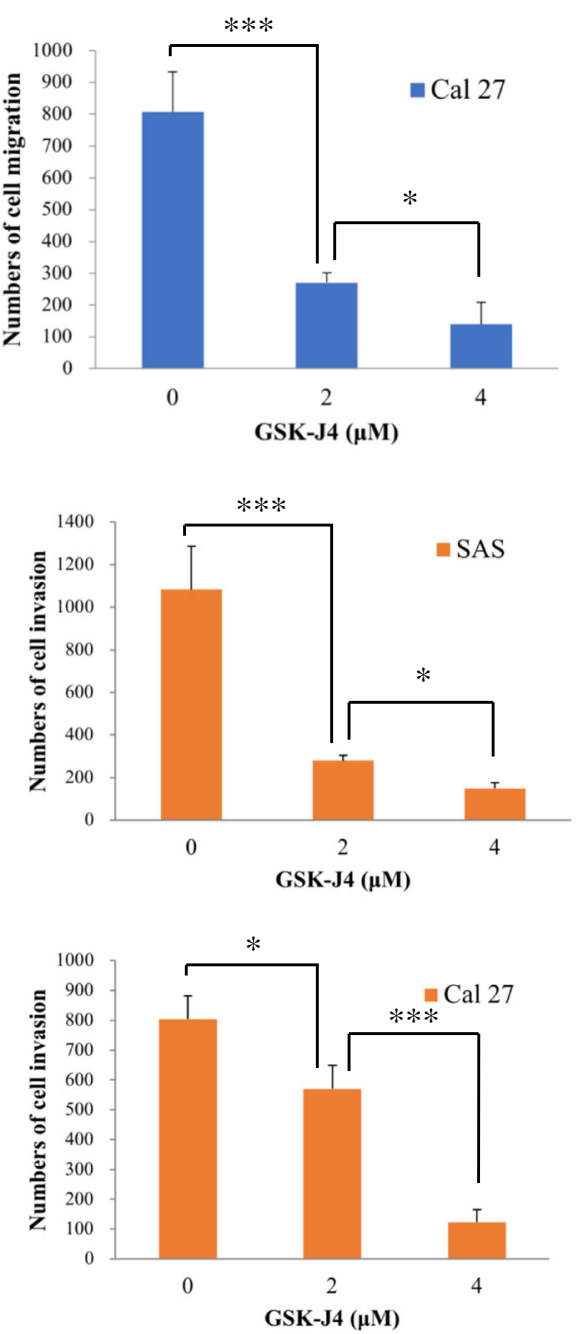

Fig. 4 Transwell migration and invasion assays using SAS and Cal 27 cell lines treated with GSK-J4 at different concentrations. Columns, mean: bars, standard deviation. Significant difference: ${ }^{*} P<0.05$ and ${ }^{* *} P<0.001$

human breast cancer cell line; in contrast, overexpression of UTX promotes cell migration [16]. Therefore, overexpression of UTX may lead to reduce H3K27 methylation, inhibit apoptosis, promote tumor cell transcription and distant metastasis and enhance EMT, contributing to poor prognosis. Our study concluded the overexpression of UTX was found to be associated with worse DFS and OS, indicating the significance of UTX as a tumor oncogene in OTSCC.

There were some studies which reported sex-specific difference in the expression of UTX. Xu et al. showed that higher expression of UTX was found in female mice than in male mice in most brain regions except in the amygdala [28]. This discordance may result from 


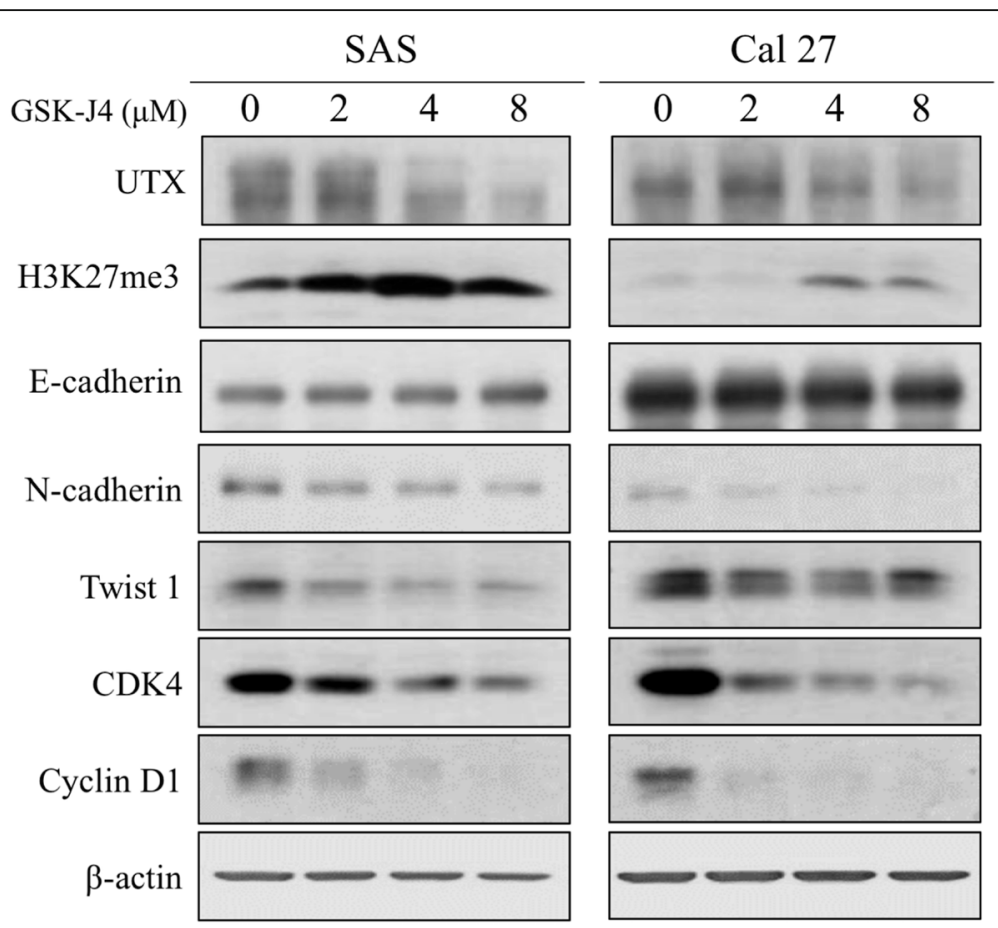

Fig. 5 Western blot analysis of UTX expression and the downstream signaling pathway in the SAS and Cal 27 cell lines. The protein expression profiles of UTX, H3K27me3 status, EMT markers, cyclin D1 and CDK4 were examined in the presence or absence of GSK-J4 treatment in the OTSCC cells by Western blotting

differences in chromatin remodeling on the $\mathrm{X}$ and $\mathrm{Y}$ chromosomes. In addition, a Belgian study demonstrated that UTX mutations were exclusively present in male TALL patients and allelic expression analysis showed UTX escapes X-inactivation in female T-ALL lymphoblasts and normal T cells [29]. In T-ALL, UTX functions as a tumor suppressor and T-ALL driven by UTX inactivation displays collateral sensitivity to pharmacologic H3K27me3 inhibition [29]. In contrast, there were no significant difference of gender distribution in our study, the percentage of female patients in the UTX overexpression and low expression groups were 9 and $8 \%$, respectively (Table 2). Although female patients were found to have longer DFS and OS than male patients in the univariate and multivariate analyses, there was no statistical difference; the better DFS and OS in the female patients may be caused by too lower proportion of female patients (only 9\%), resulting in biases existed.

GSK-J4 is a potent dual inhibitor of the H3K27me3 demethylases JMJD3 and UTX, and has been reported to be involved in many physiological and pathological processes. Growing evidence has addressed the effect of this drug in immune cells [30]. GSK-J4 was able to modulate inflammation by affecting dendritic cells, causing an increase in the expression of tolerogenic molecules, and a decrease in the secretion of proinflammatory cytokines [31]. GSK-J4 was also found to inhibit the activity of H3K27 demethylase to suppress $\mathrm{T}$ helper 17 cell differentiation as seen in in vitro studies, which suggests that it may be considered as a potential novel therapeutic target for suppressing autoimmune or inflammatory responses [32]. H3K27me3 has been related to the differentiation of normal stem cells and cancer cells, and H3K27 methylation may play a crucial role in inhibiting the maintenance of cancer stem cells [33]. In non-small cell lung cancer, GSK-J4 was able to induce cell death and inhibit the proliferation of tumor cells, irrespective of the genetic mutation status or chemotherapy resistance [34]. Therefore, GSK-J4 may represent a promising anticancer agent.

Our study also had several limitations. First, the small size of the study population may limit this study's statistical significance. Second, the percentage of female patients were relatively low (only 9\%) so it was difficult to avoid selection bias in this retrospectively designed study. Third, the association between UTX and downstream pathways was not fully investigated; additionally, the mechanism of modulation of cancer cell growth and modulation by UTX was not examined. However, to the best of our knowledge, this current study enrolled the largest number of OTSCC patients who underwent surgical resection, and may be helpful to understand the role of UTX in the prognosis of OTSCC. 


\section{Conclusion}

Our study suggests that UTX plays an important role in the process of OTSCC, and that the overexpression of UTX is an independent prognostic factor of poor prognosis in OTSCC patients who received surgical resection. Further research with a large population is needed to confirm our findings, and to clarify the complex mechanism of UTX action in OTSCC.

\section{Abbreviations}

OTSCC: oral tongue squamous cell carcinoma; UTX: ubiquitously transcribed tetratricopeptide repeat on chromosome X; H3K27: H3 lysine 27; Rb: Retinoblastoma; ECOG: Eastern Cooperative Oncology Group; PS: Performance Status; IRS: immunoreactive score; H3K27me3: trimethylation of histone $\mathrm{H} 3$ lysine 27; DFS: disease-free survival; OS: overall survival; HR: hazard ratio; Cl: confidence interval; EMT: epithelialmesenchymal transition; T-ALL: T cell acute lymphoblastic leukemia; TF: transcription factor

\section{Supplementary Information}

The online version contains supplementary material available at https://doi. org/10.1186/s12885-021-08726-3.

Additional file 1. Supplementary Fig. S1. The original data of western blot analyses.

\section{Acknowledgements}

The authors thank Drs. WT Huang and SL Wang for assessment of the immunohistochemical staining. We thank Chang Gung Medical Foundation Kaohsiung Chang Gung Memorial Hospital Tissue Bank Core Laboratory for excellent technical support.

\section{Authors' contributions}

Conceptualization, Y-H Chen; methodology, C-H Chen; software, C-Y Chien; validation, S-H Li; formal analysis, Y-Y Su; investigation, S-D Luo; resources, CY Chien; data curation, Y-Y Su and S-D Luo; writing_original draft preparation, S-H Li; writing - review and editing, Y-H Chen; visualization, C-H Chen; supervision, $\mathrm{Y}-\mathrm{H}$ Chen; project administration, $\mathrm{Y}-\mathrm{H}$ Chen; funding acquisition, $\mathrm{Y}-\mathrm{H}$ Chen. All authors have read and agreed to the published version of the manuscript.

\section{Funding}

This work was supported in part by a grant from Chang Gung Memorial Hospital, grant number CMRPG8K0601.

\section{Availability of data and materials}

The datasets used and analyzed during the current study are available from the corresponding author on reasonable request.

\section{Declarations}

\section{Ethics approval and consent to participate}

Ethical approval for this study was obtained from the Chang Gung Medical Foundation Institutional Review Board (201901388B0). All procedures used in studies involving human participants were performed in accordance with the ethical standards of the institutional research committee and the World Medical Association Declaration of Helsinki. Written informed consent was waived by the Chang Gung Medical Foundation Institutional Review Board.

\section{Consent for publication}

Not applicable.

\section{Competing interests}

The authors declare that they have no competing interests

\section{Author details}

'Department of Hematology-Oncology, Kaohsiung Chang Gung Memorial Hospital and Chang Gung University College of Medicine, No.123, Dapi Rd., Niaosong Dist, Kaohsiung City 833, Taiwan. ${ }^{2}$ School of Medicine, Chung Shan Medical University, Taichung 402, Taiwan. ${ }^{3}$ Department of Nursing, Meiho University, Pingtung 912, Taiwan. ${ }^{4}$ Institute of Medicine, Chung Shan Medical University, Department of Medical Research, Chung Shan Medical University Hospital, Taichung 402, Taiwan. ${ }^{5}$ Department of Otolaryngology, Kaohsiung Chang Gung Memorial Hospital and Chang Gung University College of Medicine, Kaohsiung, Taiwan.

Received: 20 January 2021 Accepted: 23 August 2021

Published online: 01 September 2021

\section{References}

1. The Surveillance E, and End Results (SEER) Cancer Stat Facts: Oral Cavity and Pharynx Cancer. 2013.

2. $\mathrm{Ng} \mathrm{JH}$, lyer NG, Tan MH, Edgren G. Changing epidemiology of oral squamous cell carcinoma of the tongue: a global study. Head Neck. 2017; 39(2):297-304. https://doi.org/10.1002/hed.24589.

3. Price KA, Cohen EE. Current treatment options for metastatic head and neck cancer. Curr Treat Options in Oncol. 2012;13(1):35-46. https://doi.org/10.1 007/s11864-011-0176-y.

4. Aivazian K, Ebrahimi A, Low TH, Gao K, Clifford A, Shannon K, et al. Perineural invasion in oral squamous cell carcinoma: quantitative subcategorisation of perineural invasion and prognostication. J Surg Oncol. 2015;111(3):352-8. https://doi.org/10.1002/jso.23821.

5. Daniell J, Udovicich C, Rowe D, McDowell L, Vital D, Bressel M, et al. Impact of histological Oral tongue Cancer margins on locoregional recurrence: a multi-Centre retrospective analysis. Oral Oncol. 2020;111:105004. https://doi. org/10.1016/j.oraloncology.2020.105004.

6. Fagan JJ, Collins B, Barnes L, D'Amico F, Myers EN, Johnson JT. Perineural invasion in squamous cell carcinoma of the head and neck. Arch Otolaryngol Head Neck Surg. 1998;124(6):637-40. https://doi.org/10.1001/a rchotol.124.6.637.

7. Larson AR, Kemmer J, Formeister E, El-Sayed I, Ha P, George J, et al. Beyond depth of invasion: adverse pathologic tumor features in early Oral tongue squamous cell carcinoma. Laryngoscope. 2020;130(7):1715-20. https://doi. org/10.1002/lary.28241.

8. Sharma K, Ahlawat P, Gairola M, Tandon S, Sachdeva N, Sharief MI. Prognostic factors, failure patterns and survival analysis in patients with resectable oral squamous cell carcinoma of the tongue. Radiat Oncol J. 2019;37(2):73-81. https://doi.org/10.3857/roj.2018.00577.

9. Camisasca DR, Silami MA, Honorato J, Dias FL, de Faria PA, Lourenco Sde O. Oral squamous cell carcinoma: clinicopathological features in patients with and without recurrence. ORL J Otorhinolaryngol Relat Spec. 2011;73(3):1706. https://doi.org/10.1159/000328340.

10. Lindenblatt Rde C, Martinez GL, Silva LE, Faria PS, Camisasca DR, Lourenco Sde Q. Oral squamous cell carcinoma grading systems--analysis of the best survival predictor. J Oral Pathol Med. 2012;41(1):34-9. https://doi.org/1 0.1111/j.1600-0714.2011.01068.x.

11. Lan F, Bayliss PE, Rinn JL, Whetstine JR, Wang JK, Chen S, et al. A histone H3 lysine 27 demethylase regulates animal posterior development. Nature. 2007;449(7163):689-94. https://doi.org/10.1038/nature06192.

12. van Haaften G, Dalgliesh GL, Davies H, Chen L, Bignell G, Greenman C, et al. Somatic mutations of the histone H3K27 demethylase gene UTX in human cancer. Nat Genet. 2009;41(5):521-3. https://doi.org/10.1038/ng.349.

13. Kim JH, Sharma A, Dhar SS, Lee SH, Gu B, Chan CH, et al. UTX and MLL4 coordinately regulate transcriptional programs for cell proliferation and invasiveness in breast cancer cells. Cancer Res. 2014;74(6):1705-17. https:// doi.org/10.1158/0008-5472.CAN-13-1896.

14. Lang A, Yilmaz M, Hader C, Murday S, Kunz X, Wagner N, et al. Contingencies of UTX/KDM6A Action in Urothelial Carcinoma. Cancers. 2019;11(4).

15. Li $X$, Zhang $Y$, Zheng $L$, Liu M, Chen CD, Jiang H. UTX is an escape from Xinactivation tumor-suppressor in B cell lymphoma. Nat Commun. 2018;9(1): 2720. https://doi.org/10.1038/s41467-018-05084-w.

16. Xie G, Liu X, Zhang Y, Li W, Liu S, Chen Z, et al. UTX promotes hormonally responsive breast carcinogenesis through feed-forward transcription regulation with estrogen receptor. Oncogene. 2017;36(39):5497-511. https:// doi.org/10.1038/onc.2017.157. 
17. Zhou Z, Zhang HS, Liu Y, Zhang ZG, Du GY, Li H, et al. Loss of TET1 facilitates DLD1 colon cancer cell migration via H3K27me3-mediated downregulation of E-cadherin. J Cell Physiol. 2018;233(2):1359-69. https://doi. org/10.1002/jcp.26012.

18. Suva ML, Riggi N, Bernstein BE. Epigenetic reprogramming in cancer. Science. 2013;339(6127):1567-70. https://doi.org/10.1126/science.1230184.

19. Wang JK, Tsai MC, Poulin G, Adler AS, Chen S, Liu H, et al. The histone demethylase UTX enables RB-dependent cell fate control. Genes Dev. 2010; 24(4):327-32. https://doi.org/10.1101/gad.1882610.

20. Shen Y, Guo X, Wang Y, Qiu W, Chang Y, Zhang A, et al. Expression and significance of histone H3K27 demethylases in renal cell carcinoma. BMC Cancer. 2012;12(1):470. https://doi.org/10.1186/1471-2407-12-470.

21. Remmele W, Stegner HE. Recommendation for uniform definition of an immunoreactive score (IRS) for immunohistochemical estrogen receptor detection (ER-ICA) in breast cancer tissue. Pathologe. 1987;8(3):138-40.

22. Chen YH, Chien CY, Fang FM, Huang TL, Su YY, Luo SD, et al. Nox4 overexpression as a poor prognostic factor in patients with oral tongue squamous cell carcinoma receiving surgical resection. J Clin Med. 2018; $7(12)$.

23. Zhang F, Xu L, Xu L, Xu Q, Li D, Yang Y, et al. JMJD3 promotes chondrocyte proliferation and hypertrophy during endochondral bone formation in mice. J Mol Cell Biol. 2015;7(1):23-34. https://doi.org/10.1093/jmcb/mjv003.

24. Gameiro SF, Kolendowski B, Zhang A, Barrett JW, Nichols AC, Torchia J, et al. Human papillomavirus dysregulates the cellular apparatus controlling the methylation status of H3K27 in different human cancers to consistently alter gene expression regardless of tissue of origin. Oncotarget. 2017;8(42): 72564-76. https://doi.org/10.18632/oncotarget.19885.

25. Lee YM, Kim SH, Kim MS, Kim DC, Lee EH, Lee JS, et al. Epigenetic role of histone lysine methyltransferase and demethylase on the expression of transcription factors associated with the epithelial-to-mesenchymal transition of lung adenocarcinoma metastasis to the brain. Cancers. 2020; 12(12).

26. Wang L, Shilatifard A. UTX mutations in human Cancer. Cancer Cell. 2019; 35(2):168-76. https://doi.org/10.1016/j.ccell.2019.01.001.

27. Benyoucef A, Palii CG, Wang C, Porter CJ, Chu A, Dai F, et al. UTX inhibition as selective epigenetic therapy against TAL1-driven T-cell acute lymphoblastic leukemia. Genes Dev. 2016;30(5):508-21. https://doi.org/10.11 01/gad.276790.115.

28. Xu J, Deng X, Watkins R, Disteche CM. Sex-specific differences in expression of histone demethylases Utx and Uty in mouse brain and neurons. J Neurosci. 2008;28(17):4521-7. https://doi.org/10.1523/JNEUROSCI.5382-07.2 008.

29. Van der Meulen J, Sanghvi V, Mavrakis K, Durinck K, Fang F, Matthijssens F, et al. The H3K27me3 demethylase UTX is a gender-specific tumor suppressor in T-cell acute lymphoblastic leukemia. Blood. 2015;125(1):13-21. https://doi.org/10.1182/blood-2014-05-577270.

30. Donas C, Carrasco M, Fritz M, Prado C, Tejon G, Osorio-Barrios F, et al. The histone demethylase inhibitor GSK-J4 limits inflammation through the induction of a tolerogenic phenotype on DCs. J Autoimmun. 2016;75:10517. https://doi.org/10.1016/j.jaut.2016.07.011.

31. Kruidenier L, Chung CW, Cheng Z, Liddle J, Che K, Joberty G, et al. A selective jumonji H3K27 demethylase inhibitor modulates the proinflammatory macrophage response. Nature. 2012;488(7411):404-8. https://doi.org/10.1038/nature11262.

32. Liu Z, Cao W, Xu L, Chen X, Zhan Y, Yang Q, et al. The histone H3 lysine-27 demethylase Jmjd3 plays a critical role in specific regulation of Th17 cell differentiation. J Mol Cell Biol. 2015;7(6):505-16. https://doi.org/10.1093/ jmcb/mjv022.

33. Sakaki H, Okada M, Kuramoto K, Takeda H, Watarai H, Suzuki S, et al. GSKJ4, a selective Jumonji H3K27 demethylase inhibitor, effectively targets ovarian Cancer stem cells. Anticancer Res. 2015;35(12):6607-14.

34. Watarai H, Okada M, Kuramoto K, Takeda H, Sakaki H, Suzuki S, et al. Impact of H3K27 demethylase inhibitor GSKJ4 on NSCLC cells alone and in combination with metformin. Anticancer Res. 2016;36(11):6083-92. https:/ doi.org/10.21873/anticanres.11198.

\section{Publisher's Note}

Springer Nature remains neutral with regard to jurisdictional claims in published maps and institutional affiliations.

\section{Ready to submit your research? Choose BMC and benefit from:}

- fast, convenient online submission

- thorough peer review by experienced researchers in your field

- rapid publication on acceptance

- support for research data, including large and complex data types

- gold Open Access which fosters wider collaboration and increased citations

- maximum visibility for your research: over $100 \mathrm{M}$ website views per year

At BMC, research is always in progress.

Learn more biomedcentral.com/submissions 